Article

\title{
Action Spectrum on UVA Irradiation for Formation of Persistent Pigmentation in Normal Japanese Individuals
}

\author{
Kazuhisa Maeda \\ School of Bioscience and Biotechnology, Tokyo University of Technology, 1404-1 Katakuramachi, Hachioji, \\ Tokyo 192-0982, Japan; kmaeda@stf.teu.ac.jp; Tel.: +81-42-6372442
}

Received: 23 September 2017; Accepted: 12 December 2017; Published: 15 December 2017

\begin{abstract}
The minimum exposure required to produce persistent pigmentation (PP) on the skin of normal Japanese subjects was evaluated by means of monochromatic irradiation on the back using a high-intensity monochromator. PP was induced within the range of wavelengths up to $468 \mathrm{~nm}$, with a peak from 330 to $370 \mathrm{~nm}$, but it was not observed at 482 or $497 \mathrm{~nm}$. When the PP production curve was obtained taking the spectral distribution of sunlight into account, it showed a peak at $340 \mathrm{~nm}$ centering in the UVA region and extending into the region up to $396 \mathrm{~nm}$. Thus, it appears that solar UVA participates in PP formation.
\end{abstract}

Keywords: immediate pigment darkening; persistent pigmentation; UVA

\section{Introduction}

Dark-brown persistent pigmentation (PP) appears soon after exposure to sunlight but is distinct from the immediate pigment darkening (IPD), which is dark-gray in color and subsides rapidly with the passage of time. Its mechanism has not been clarified yet but may involve photo-oxidation of melanin precursors in the basal layer of the epidermis [1], in contrast to the mechanism of IPD, which is believed to involve photo-oxidation of existing melanin in the epidermis [2-4] or a change in the distribution of melanosomes in epidermal cells [5]. The causal wavelength range for IPD is said to be from UVA (320-400 nm) to visible $(<420 \mathrm{~nm})$ [6,7]. Pathak et al. also reported on the influence of visible wavelength $(400-640 \mathrm{~nm})$, but there are substantial differences among the previous reports [8]. Further, the action spectrum of persistent pigment darkening (PPD; at 2-4 h after exposure) in the UVA region decreases very slowly to longer wavelengths [9]. However, the action spectrum of PP has not yet been studied in Japanese individuals. We used a high-intensity monochromator to irradiate the back of our subjects, and measured the minimum IPD-inducing dose (MIPDD) and the minimum PP-inducing dose (MPPD). Furthermore, the action spectrum was reevaluated, taking into account the spectral distribution of sunlight.

\section{Materials and Methods}

\subsection{Subject}

Ten healthy Japanese men, 24-36 years of age, with no history of exposure to sunlight on the back in the previous 6 months, were used to obtain the action spectrum of PP. All volunteers had skin type III or IV. All volunteers had given their informed consent to participate, and the study protocol was approved by the Ethics Committee. 


\subsection{Light Source}

For irradiation, a monochromator CRM-FM (JASCO Co., Tokyo, Japan) designed in this laboratory was employed. The light source was a $5 \mathrm{~kW}$ xenon arc lamp (Ushio Electric Co., Tokyo, Japan). Its spectral output extended strongly and continuously over the wavelengths from the ultraviolet to the visible light range. The sites with a uniform skin color were used for the examination. The pigmentation site was removed from the measured region. Thirteen wavelengths from 320 to $497 \mathrm{~nm}, 10 \mathrm{~nm} \pm 5 \mathrm{~nm}$, were employed. The energy output at each wavelength was measured using a calibrated thermocouple (Nippon Bunko Co., Tokyo, Japan).

\subsection{Irradiation and Measurement}

Intensity at each wavelength was as follows: $0.87 \mathrm{~mW} / \mathrm{cm}^{2}$ at $320 \mathrm{~nm}, 3.1 \mathrm{~mW} / \mathrm{cm}^{2}$ at $336 \mathrm{~nm}$, $4.9 \mathrm{~mW} / \mathrm{cm}^{2}$ at $351 \mathrm{~nm}, 5.8 \mathrm{~mW} / \mathrm{cm}^{2}$ at $366 \mathrm{~nm}, 6.0 \mathrm{~mW} / \mathrm{cm}^{2}$ at $382 \mathrm{~nm}, 6.1 \mathrm{~mW} / \mathrm{cm}^{2}$ at $396 \mathrm{~nm}$, $5.6 \mathrm{~mW} / \mathrm{cm}^{2}$ at $411 \mathrm{~nm}, 5.1 \mathrm{~mW} / \mathrm{cm}^{2}$ at $425 \mathrm{~nm}, 4.9 \mathrm{~mW} / \mathrm{cm}^{2}$ at $439 \mathrm{~nm}, 5.3 \mathrm{~mW} / \mathrm{cm}^{2}$ at $454 \mathrm{~nm}$, $5.7 \mathrm{~mW} / \mathrm{cm}^{2}$ at $468 \mathrm{~nm}, 5.9 \mathrm{~mW} / \mathrm{cm}^{2}$ at $482 \mathrm{~nm}$, and $5.6 \mathrm{~mW} / \mathrm{cm}^{2}$ at $497 \mathrm{~nm}$. Irradiation was applied for $1,2,5,10,20$, and $80 \mathrm{~min}$. Six sites $(20 \mathrm{~mm} \times 25 \mathrm{~mm})$ were horizontally made at intervals of $5 \mathrm{~mm}$, and they were irradiated with UVA of each wavelength for 1,2,5, 10, 20, and $80 \mathrm{~min}$. Thirteen sites $(20 \mathrm{~mm} \times 25 \mathrm{~mm}$ ) were vertically made at intervals of $5 \mathrm{~mm}$, and they were irradiated with 13 wavelengths of UVA (Figure 1). MIPDD and MPPD ( $24 \mathrm{~h}$ and 1 week) were obtained based on visual evaluation immediately after irradiation (MIPDD), as well as at $24 \mathrm{~h}$ and 1 week later, to calculate MPPD ( $24 \mathrm{~h}$ and 1 week). The action spectrum was obtained as the mean relative effect-wavelength curve for each individual. Skin color value was measured on unexposed back with a Chroma Meter CR-200 (Minolta, Osaka, Japan). The spectral distribution of sunlight was measured with a grating spectroradiometer (MS-701, EKO Instruments Co., Tokyo, Japan) on a fine day and on a cloudy day in May in Yokohama $\left(35^{\circ} \mathrm{N}\right)$.

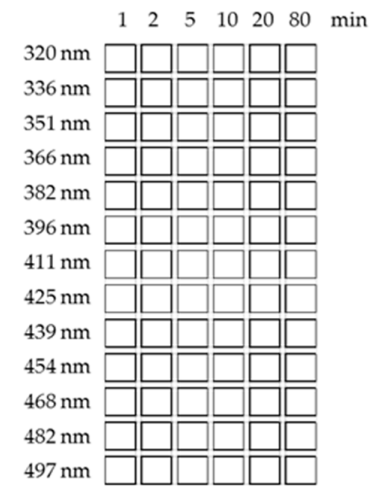

Figure 1. Irradiation wavelength and irradiation time.

\section{Results and Discussion}

\subsection{IPD and PP}

Figure 2 shows percentage positivity of darkening in 10 examinees under irradiation at each wavelength. From 336 to 411 nm, IPD was noted in 100\%, but in the visible region above $425 \mathrm{~nm}$, it was seen in less than $40 \%$. Further, in the range of wavelengths from 320 to $396 \mathrm{~nm}$ that caused IPD, $\mathrm{PP}$ was noted at $24 \mathrm{~h}$ and 1 week after irradiation. The percentage positivity of PP is clearly different from that of IPD. IPD was induced in the wavelength range from 320 to $468 \mathrm{~nm}$, but not at 482 or $497 \mathrm{~nm}$. On the other hand, PP was induced in the wavelength range from 320 to $396 \mathrm{~nm}$, but not at $411,425,439,454,468,482$, or $497 \mathrm{~nm}$. In the region of wavelengths exceeding $425 \mathrm{~nm}, 4$ men out of 10 showed IPD, while 6 men did not, and none of them showed PP. These results indicate that IPD induced by UVA does not become transformed to PP. 


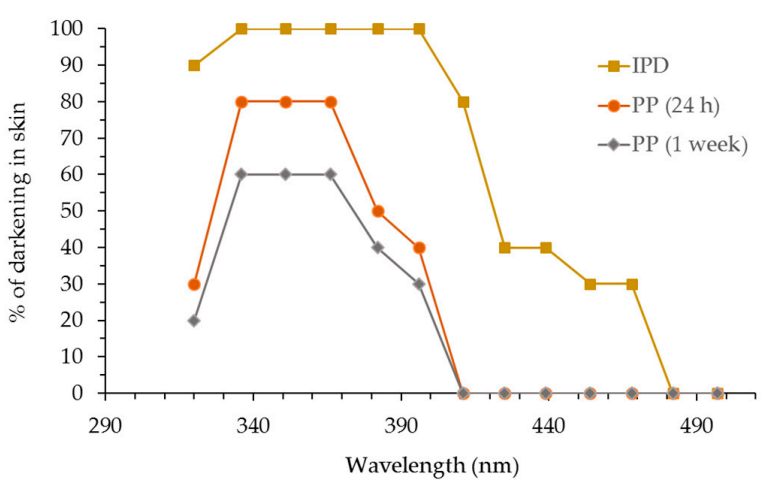

Figure 2. Percentages of immediate pigment darkening (IPD) and persistent pigmentation (PP). Positivity of PP was estimated visually at $24 \mathrm{~h}$ and 1 week after irradiation.

In addition, MIPD is reported to be different depending on skin type in Caucasians [10,11], and the appearance of IPD in response to visible light showed a dependence on inter-individual differences of wavelength sensitivity. Further, MPPD showed a significant dependence on skin color in Japanese. Given the inter-individual differences of reactivity to wavelength, it was considered more appropriate to obtain the action spectrum for PP as a mean curve based on each individual action spectrum, instead of obtaining a mean value of MIPD at each wavelength.

\subsection{Action Spectrum of PP on UVA Irradiation}

Figure 3 shows the action spectrum of PP on UVA irradiation. It has a maximum of $320 \mathrm{~nm}$, followed by a rapid decrease with increasing wavelength of up to $396 \mathrm{~nm}$ (the relative effect at $396 \mathrm{~nm}$ is only $1 / 10$ of that at $320 \mathrm{~nm}$ ), then a plateau of up to $454 \mathrm{~nm}$, and a disappearance at $482 \mathrm{~nm}$. The relative effect-wavelength curve for PP obtained by the monochromator did not correspond with the reported action curve of IPD in Japanese [12], showing a maximum at $320 \mathrm{~nm}$ in the UVA region and decreasing gradually towards $400 \mathrm{~nm}$.

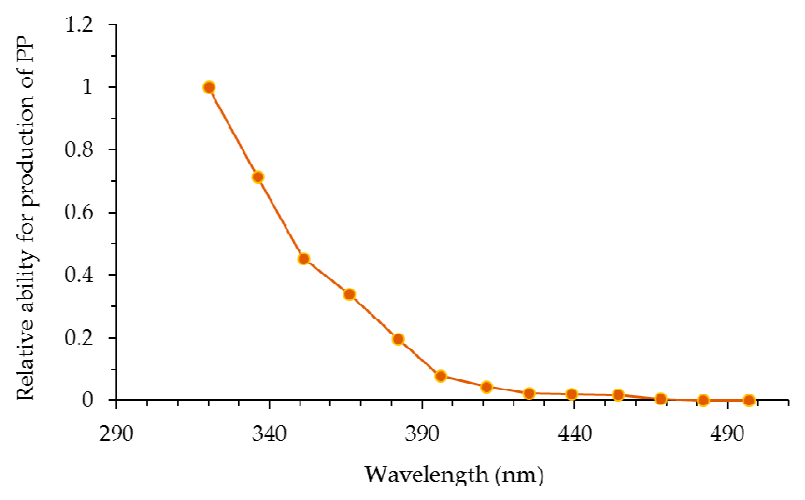

Figure 3. Relative effect-wavelength curve of persistent pigmentation (PP).

\subsection{Induction of PP by Solar Light}

Figure 4 shows the spectral distributions of UV rays in sunlight on a fine day and a cloudy day. Figure 5 shows the production curves of PP by the sunlight. Solar UV rays showed an energy minimum at $300 \mathrm{~nm}$ in the range from UVB to visible, exhibiting a linear enhancement with increasing wavelength. When this energy distribution was taken into account, the production curve of PP by sunlight showed a peak at $340 \mathrm{~nm}$, followed by a rapid decrease with increasing wavelength up to $411 \mathrm{~nm}$ on a fine day. PP production on a cloudy day was one-third of that on a fine day, showing a broad distribution up to $396 \mathrm{~nm}$ with a peak at $340 \mathrm{~nm}$. 
The action curve of PP by sunlight showed a peak centered at $340 \mathrm{~nm}$ and distributed up to $411 \mathrm{~nm}$, being different from that obtained with the monochromator. The action spectrum of PP on the skin exposed to sunlight would be influenced by the angle of incidence, intensity, season, time, surface of the skin, site, and other factors. Taking into account the spectrum of sunlight, however, Figure 5 shows the expected curve of PP caused by sunlight. At higher latitudes, the UVA component becomes larger than the UVB component in sunlight $[9,10]$, so it has been considered that UVA plays a more important role in PP. A similar change in sunlight is seen from afternoon to sunset. It was suggested that, under exposure to the sunlight, PP is generally associated with longer wavelengths of UVA in sunlight, as compared with the action spectrum measured with a monochromator.

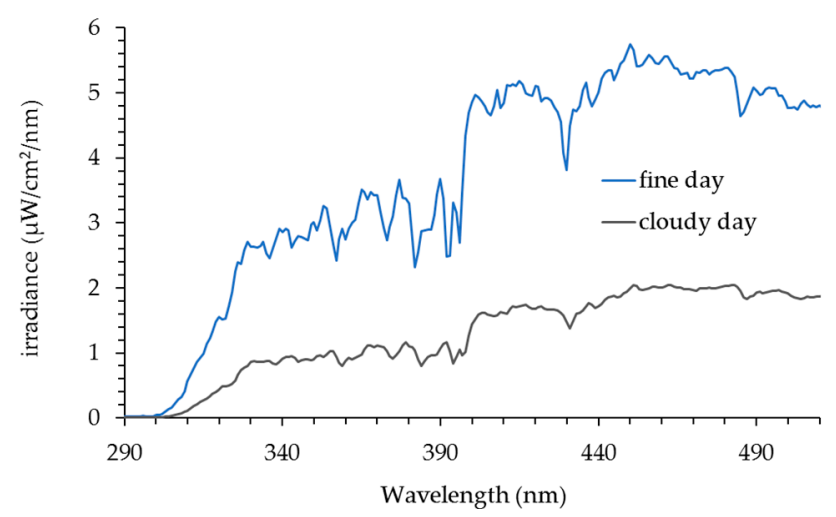

Figure 4. Spectral distribution $(280-500 \mathrm{~nm})$ of sunlight measured at noon on a fine day and on a cloudy day in May in Yokohama $\left(35^{\circ} \mathrm{N}\right)$.

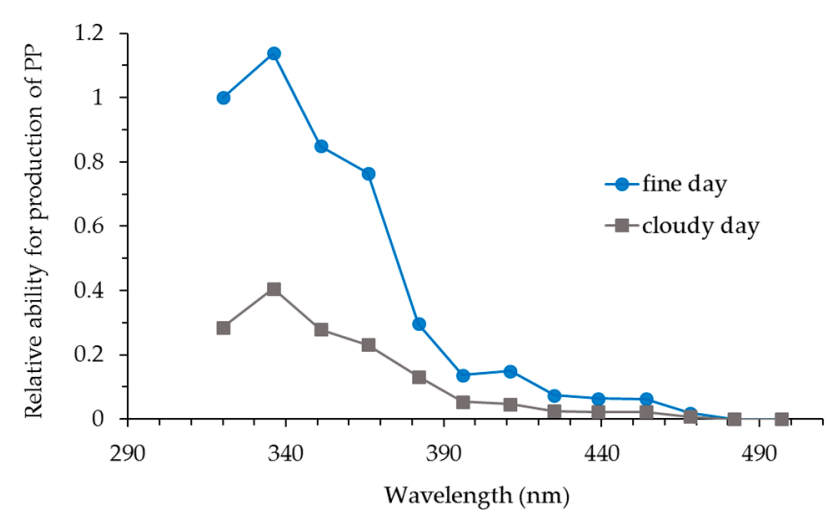

Figure 5. Product curve of persistent pigmentation (PP) by sunlight calculated by spectral distribution of sunlight in Figure 4.

\section{Conclusions}

PP was induced within the range of the UVA region, with a peak from 330 to $370 \mathrm{~nm}$, but it was not observed in the visible light so much. When the PP production curve was obtained taking the spectral distribution of sunlight into account, it showed a peak at $340 \mathrm{~nm}$ centering in the UVA region, and extending into the region up to $411 \mathrm{~nm}$. Thus, it appears that solar UVA participates in PP formation and the action spectrum of PP is clearly different from that of IPD.

Conflicts of Interest: The author declares no conflict of interest. 


\section{References}

1. Maeda, K.; Hatao, M. Involvement of photooxidation of melanogenic precursors in prolonged pigmentation induced by ultraviolet A. J. Investig. Dermatol. 2004, 122, 503-509. [CrossRef] [PubMed]

2. Miescher, G.; Minder, H. Untersuchungen über die durch langwelliges Ultraviolett hervorgerufene Pigmetdunkelung. Strahlentherapie 1939, 66, 6-23.

3. Pathak, M.A.; Stratton, K. Free radicals in human skin before and after exposure to light. Arch. Biochem. Biophys. 1968, 123, 468-476. [CrossRef]

4. Beitner, H.; Wennersten, G. A qualitative and quantitative transmission electronmicroscopic study of the immediate pigment darkening reaction. Photodermatology 1985, 2, 273-278. [PubMed]

5. Lavker, R.M.; Kaidbey, K.H. Redistribution of melanosomal complexes within keratinocytes following UV-A irradiation: A possible mechanism for cutaneous darkening in man. Arch. Dermatol. Res. 1982, 272, 215-228. [CrossRef] [PubMed]

6. Hausser, I. Ueber spezifische Wirkungen des langwelliges ultravioletten Lichts auf die menschliehe Haut. Strahlentherapie 1938, 62, 315-322.

7. Henschke, U.; Schultze, R. Untersuchungen zum Problem der ultraviolett Dosimetrie III. Überpigmentierung durch langwelliges Ultraviolett. Strahlentherapie 1939, 64, 14-42.

8. Pathak, M.A.; Riley, E.C.; Fitzpatrick, T.B. Melanogenesis in human skin following exposure to long-wave ultraviolet and visible light. J. Investig. Dermatol. 1962, 39, 435-443. [CrossRef] [PubMed]

9. Chardon, A.; Moyal, D.; Hourseau, C. Persistent pigment-darkening response as a method for evaluation of ultraviolet A protection assays. In Sunscreens: Development, Evaluation and Regulatory Aspects, 2rd ed.; Lowe, N.J., Shaath, N.A., Pathak, M.A., Eds.; Marcel Dekker Inc.: New York, NY, USA, 1997; pp. 559-582.

10. Beitner, H.; Wennersten, G. Clinical aspects of the immediate pigment darkening (IPD) reaction in normal individuals. Acta Derm. Venereol. 1980, 60, 323-326. [PubMed]

11. Agin, P.P.; Desrochers, D.L.; Sayre, R.M. The relationship of immediate pigment darkening to minimal erythemal dose, skin type, and eye color. Photodermatology 1985, 2, 288-294. [PubMed]

12. Kawada, A. UVB-induced erythema, delayed tanning, and UVA-induced immediate tanning in Japanese skin. Photodermatology 1986, 3, 327-333. [PubMed]

(C) 2017 by the author. Licensee MDPI, Basel, Switzerland. This article is an open access article distributed under the terms and conditions of the Creative Commons Attribution (CC BY) license (http:/ / creativecommons.org/licenses/by/4.0/). 